
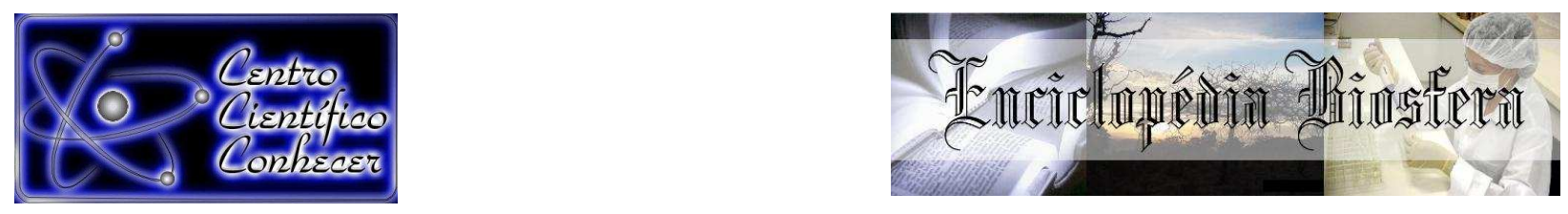

\title{
EFICIÊNCIA DE INSETICIDAS NO CONTROLE DE Spodoptera frugiperda (J. E. Smith) (Lepidoptera: Noctuidae) ALIMENTADAS COM FOLHAS DE MILHO, FEIJÃO, SOJA E SORGO
}

Givanildo Sousa Gonçalves' ${ }^{1}$, Rosinei da Silva Cardoso², Welk Salathyel Albino de Oliveira², Raphael Maia Aveiro Cessa ${ }^{3}$, Elmo Pontes de Melo ${ }^{4}$

1 Mestrando da Universidade do Estado de Mato Grosso, (givanildosg2011@hotmail.com), Alta Floresta MT-Brasil,

2 Instituto Federal de Educação, Ciência e Tecnologia de Mato Grosso, Confresa MT-Brasil

3 Professor Doutor do Instituto Federal de Educação, Ciência e Tecnologia de Mato Grosso, Confresa MT-Brasil

4 Científica Serviços Agronômicos, Dourados MS-Brasil

Recebido em: 08/04/2016 - Aprovado em: 30/05/2016 - Publicado em: 20/06/2016 DOI: 10.18677/Enciclopedia Biosfera 2016049

\begin{abstract}
Avaliou-se neste estudo a eficiência de controle dos inseticidas Curyom 550 EC, Endosulfan AG, Engeo Pleno e Klorpan 480 EC e água destilada como testemunha, sobre a mortalidade de lagartas de Spodoptera. frugiperda de $1^{\circ}$ e $3^{\text {o }}$ instar, alimentadas com folhas de milho, sorgo, soja e feijão. Como delineamento experimental foi utilizado o modelo de blocos casualizados, com cinco repetições. Cada parcela experimental foi representada por uma placa de petri, onde foram colocadas 10 lagartas de $1^{\circ}$ ou $3^{\circ}$ instar, sobre papel filtro. A eficiência de controle dos inseticidas foi calculada diariamente por meio da contagem de lagartas mortas em cada placa de petri, até atingir a mortalidade de todas as lagartas. Todos os inseticidas testados promoveram controle total das lagartas em até 72 horas após o inicio do ensaio, tanto para lagartas de $1^{\circ}$ ou $3^{\circ}$ instar. Os inseticidas que apresentaram menor velocidade na mortalidade das lagartas foram Engeo Pleno em sorgo e feijoeiro, Endosulfan AG em sorgo.
\end{abstract}

RESUMO

PALAVRAS - CHAVE: alimentação, controle químico, inseto.

\section{EFFICIENCY OF PESTICIDES IN THE CONTROL OF Spodoptera frugiperda (JE Smith) (Lepidoptera: Noctuidae) FED WITH CORN LEAVES, SOY, BEAN AND SORGHUM}

\section{ABSTRACT}

We evaluated in this study the insecticides control efficiency of the Curyom $550 \mathrm{EC}$, Endosulfan AG, Engeo Pleno and Klorpan 480 EC and distilled water as a control, on the mortality caterpillar Spodoptera frugiperda of 1st and 3rd instar, fed with leaves of corn, sorghum, soybeans and beans. As experimental design model we used a randomized block design with five replications. Each plot was represented by a petri 
dish, which were placed 10 caterpillars of 1 st or 3rd instar on filter paper. The control efficiency of the insecticides was calculated daily by counting dead caterpillars in each petri dish until mortality of all caterpillars. All insecticides tested promoted total control of caterpillars within 72 hours after the start of the test, both caterpillars 1st or 3rd instar. Insecticides that had lower mortality rate of caterpillars were Engeo Pleno in sorghum and beans, Endosulfan AG in sorghum.

KEYWORDS: feeding, control, insect

\section{INTRODUÇÃO}

Spodoptera frugiperda é um inseto que se alimenta das principais culturas agrícolas das Américas. Surtos ocorrem regularmente em áreas produtoras e as populações facilmente atingem ou superam os níveis de danos econômicos, causando enormes prejuízos aos produtores (TOSCANO et al., 2012). A praga tem atingido populações tão altas que exigem medidas de controle logo após a emergência da planta.

No Brasil o milho, soja, sorgo e o feijoeiro ocupam grandes áreas agrícolas em cultivo, com produtividade média muito baixa. Entre os fatores que influencia negativamente na produtividade de culturas agrícolas, as pragas têm elevada participação (MICHELOTTO et al., 2011). Entre elas as lagartas lideram o ranking de destruição das lavouras.

Entre as principais lagartas $S$. frugiperda (J. E. Smith) (Lepidoptera: Noctuidae), é a praga que causa os maiores danos econômicos. Segundo GALLO et al., 2002, S. frugiperda, através da destruição das folhas, pode reduzir a produtividade do milho em até $20 \%$, sendo o período crítico de seu ataque a época próxima ao florescimento.

S. frugiperda é originaria das zonas tropicais e subtropicais da América, mas também está distribuída amplamente pelas zonas temperadas do continente norteamericano. Alimenta-se inicialmente raspando o tecido vegetal de um lado da folha onde a epiderme do lado oposto permanece intacta e pode atacar em todas as fases do desenvolvimento das culturas (ARAÚJO et al., 2011; WANGEN et al., 2015).

Em sorgo a praga atinge todas as fases de desenvolvimento, ficando prejudicado pela destruição das folhas, reduzindo à área fotossintética e consequentemente a produção. Em milho as lagartas penetram nas plantas atingindo o cartucho, alimentando-se das folhas jovens, destruindo completamente as pequenas plantas e podem também se alimentar das espigas (OTA et al., 2011; CAMPANHA et al., 2012). Nas culturas da soja e do feijoeiro a lagarta ocorre em qualquer época em que a planta é cultivada, e seu ataque pode iniciar-se logo nos primeiros dias após a emergência das plantas.

O método químico de controle é o mais utilizado contra $S$. frugiperda, pela sua rápida eficiência e fácil aplicação, mas muitas vezes é utilizado desordenadamente, causando problemas ao meio ambiente (OTA et al., 2011). Além disso, já foi registrada a ocorrência de populações resistentes a alguns agrotóxicos tradicionais como a lambda-cialotrina e organofosforados, (DIEZ-RODRIGUEZ \& OMOTO, 2001).

O presente trabalho teve como objetivo avaliar a eficiência de diferentes inseticidas de grupos químicos distintos no controle de lagartas de $S$. frugiperda de 
$1^{\circ}$ e $3^{\circ}$ instar, a fim de determinar se está ocorrendo resistência da praga às moléculas.

\section{MATERIAL E MÉTODOS}

O ensaio laboratorial foi conduzido com cinco repetições no delineamento experimental de blocos casualizados e cinco tratamentos (quatro inseticidas diferentes e água como controle) (Tabela 1) utilizados em soluções para imersão de secções foliares de milho, soja, feijoeiro e sorgo e fornecidas às lagartas $S$. frugiperda para avaliar a mortalidade populacional.

As parcelas experimentais foram constituídas por placas de Petri de 19 centímetros de diâmetro, forradas com papel filtro umedecidocom $1,0 \mathrm{~mL}$ de água destilada onde foram colocadas 10 lagartas de $1^{\circ}$ instar (experimento 1) e 3 lagartas de $3^{\circ}$ instar (experimento 2) fornecidas pelo biolaboratório do Centro Universitário da Grande Dourados (UNIGRAN). As parcelas experimentais foram mantidas sobre bancada de mármore alocada em sala climatizada, regulada a $25 \pm 2^{\circ} \mathrm{C}$, fotofase de 12 horas.

Para o fechamento da placa utilizaram-se tampas de vidro. As seções foliares provenientes das espécies vegetais fornecidas às lagartas foram trocadas a cada 24 horas, sempre previamente imersas em soluções contendo inseticidas descritos na tabela 1. A mortalidade das lagartas de $S$. frugiperda foi avaliada diariamente até 0 terceiro dia após implantação do ensaio. Sobre essa característica calculou-se a eficiência relativa segundo ABBOTT, 1925.

A eficiência relativa é obrigatória nos laudos de testes de Eficiência e Praticabilidade Agronômica de Agrotóxicos e afins enviados para o Ministério da Agricultura, Pecuária e Abastecimento (MAPA) para registro de novos produtos (Instrução Normativa SDA no 36, de 24 de novembro de 2009). O referido órgão público considera eficientes os tratamentos com valores de controle positivo superior a $80 \%$ em relação à testemunha. A eficiência relativa explica melhor e/ou é mais válida do que as sugestões dos testes de média, como por exemplo: o fato de um tratamento diferenciar ou não da testemunha não significa que esse seja eficiente. Assim, no presente trabalho consideraram-se eficientes os tratamentos com eficiência relativa sobre a mortalidade das lagartas acima de $80 \%$.

TABELA 1. Inseticidas utilizados nas soluções para imersão das secções das folhas de milho, soja, feijoeiro e sorgo.

\begin{tabular}{|c|c|c|}
\hline Inseticidas & Ingrediente ativo/grupo químico & Dose $\left(\mathrm{L} \mathrm{ha}^{-1}\right)^{\star}$ \\
\hline Testemunha & & - \\
\hline Curyom 550 EC & $\begin{array}{l}\text { Lufenurom }\left(500 \mathrm{~g} \text { i.a L L }{ }^{-1}\right) / \text { Benzoiluréia }+ \\
\text { Profenofós }\left(50 \mathrm{~g} \text { i.a L }{ }^{-1}\right) / \text { Organofosforado }\end{array}$ & 0350 \\
\hline Endosulfan AG & Endossulfan $\left(635 \mathrm{~g}\right.$ i.a L $\left.\mathrm{L}^{-1}\right) /$ Ciclodienoclorado & 1,500 \\
\hline o Pleno & $\begin{array}{l}\text { Lambda-Cialotrina }(106 \mathrm{~g} \text { i.a L L }) \text { / Piretróide }+ \\
\text { Tiametoxam }\left(146 \mathrm{~g} \text { i.a } \mathrm{L}^{-1}\right) / \text { Neonicotinóide }\end{array}$ & 0,150 \\
\hline Klorpan 480 EC & Clorpirifós $\left(489,80 \mathrm{~g}_{\text {i.a L }}^{-1}\right)$ / Organofosforado & 0,500 \\
\hline
\end{tabular}

*Litros do produto comercial utilizado por hectare em uma quantidade de $600 \mathrm{~L}$ de água. 


\section{RESULTADOS E DISCUSSÃO}

Até 48 horas após a implantação do ensaio observou-se eficiência relativa de $100 \%$ sobre a mortalidade das lagartas $S$. frugiperda de $1^{\circ}$ e $3^{\circ}$ instar quando alimentada com folhas de milho e soja imersas em solução contendo os inseticidas avaliados (Tabelas 2, 3, 4 e 5).

Quando alimentadas com folhas de feijoeiro e sorgo imersas em solução contendo o inseticida Engeo Pleno houve eficiência relativa de $100 \%$ sobre a mortalidade de lagartas de $S$. frugiperda em $1^{\circ}$ instar até 72 horas da implantação do ensaio. Este mesmo comportamento foi observado para as folhas de sorgo com uso do inseticida Endosulfan AG. Os demais inseticidas promoveram a mortalidade de lagartas de $1^{\circ}$ instar até 48 horas da implantação do ensaio. Sobre lagartas de $S$. frugiperda em $3^{\circ}$ instar todos os inseticidas testados tiveram eficiência relativa de $100 \%$ sobre a população das referidas lagartas em até 48 horas da implantação do ensaio (Tabelas 6, 7, 8 e 9).

A eficiência relativa dos inseticidas testados sobre a mortalidade de pragas agrícolas está relacionada com os seus modos de ação e/ou absorção pelo inseto, podendo ou não ter ação tóxica imediata com influência sobre seu desenvolvimento, residual, associações em calda e tipo de formulação desses produtos e que a quantidade do ingrediente ativo do inseticida depositada sobre a folha também é determinante para toxidez de insetos (CESSA et al., 2013).

O comportamento semelhante observado sobre o tempo de eficiência relativa da mortalidade de populações de lagartas de S.frugiperda de $1^{\circ}$ e $3^{\circ}$ instar em diferentes espécies vegetais possivelmente, está relacionado pelo fato de se tratar de uma praga polífaga, e que a fase de desenvolvimento não interferem sobre sua preferência alimentar(SILVA et al., 2012).

A diferença entre produtos testados quanto à eficiência relativa sobre a mortalidade de $S$. frugiperda nos períodos avaliados ocorre devido aos seus diferentes mecanismos de ação. (BELLETTINI et al., 2011), avaliando mortalidade de $S$. frugiperda com a aplicação de chlorantraniliprole+lambdacialotrina (Ampligo) $5+2,5 ; 10+5$ e 20+10 g; espinosade (Tracer) $60 \mathrm{~g}$; lufenuron (Match EC) $20 \mathrm{~g}$, constataram que chlorantraniliprole+lambdacialotrina (Ampligo) 5+2,5 g na avaliação aos 14 dias não diferiu da testemunha. 
TABELA 2. Eficiência relativa da mortalidade de lagartas $S$. frugiperda alimentadas com seções de folhas de milho imersas em inseticidas 24, 48, e 72 horas após implantação do experimento, calculada com base na mortalidade de lagartas - Lagartas $1^{\circ}$ instar.

Inseticidas

Ingrediente ativo/grupo químico

$24 \mathrm{~h} 48 \mathrm{~h} 72 \mathrm{~h}$ Eficiência (\%)

Curyom 550 EC Lufenurom (500 g i.a L $\mathrm{L}^{-1}$ ) / Benzoiluréia + Profenofós (50 g i.a L L $)$ / Organofosforado 100

Endosulfan AG Endossulfan $\left(635 \mathrm{~g}^{\mathrm{i} . \mathrm{a} \mathrm{L}^{-1}}\right) /$ Ciclodienoclorado

$100-\quad-$

Engeo Pleno Lambda-Cialotrina (106 g i.a L $\left.{ }^{-1}\right) /$ Piretróide + Tiametoxam (146 g i.a L $\left.{ }^{-1}\right) /$ Neonicotinóide 100

Klorpan 480 EC Clorpirifós $\left(489,80 \mathrm{~g}^{-1} \mathrm{~L}^{-1}\right) /$ Organofosforado

${ }^{\star}$ Dose do produto comercial utilizado por hectare em uma quantidade de $600 \mathrm{~L}$ de água

TABELA 3. Eficiência relativa da mortalidade de lagartas $S$. frugiperda alimentadas com seções de folhas de milho imersas em inseticidas 24, 48, e 72 horas após implantação do experimento, calculada com base na mortalidade de lagartas - Lagartas $3^{\circ}$ instar.

\begin{tabular}{|c|c|c|c|c|}
\hline Inseticidas & Ingrediente ativo/grupo químico & $24 \mathrm{~h}$ & $48 \mathrm{~h}$ & $72 \mathrm{~h}$ \\
\hline & & Efic & iênci & $(\%)$ \\
\hline Curyom 550 EC & Lufenurom (500 g i.a L $\left.{ }^{-1}\right) /$ Benzoiluréia + Profenofós $\left(50 \mathrm{~g}\right.$ i.a $\left.\mathrm{L}^{-1}\right)$ / Organofosforado & 67 & 100 & - \\
\hline Endosulfan AG & Endossulfan (635 g i.a L $\left.{ }^{-1}\right) /$ Ciclodienoclorado & 100 & - & - \\
\hline Engeo Pleno & Lambda-Cialotrina (106 g i.a L $\left.{ }^{-1}\right)$ / Piretróide + Tiametoxam (146 g i.a L ${ }^{-1}$ ) / Neonicotinóide & 33 & 100 & - \\
\hline Klorpan 480 EC & Clorpirifós $\left(489,80 \mathrm{~g}\right.$ i.a L $\left.{ }^{-1}\right) /$ Organofosforado & 100 & - & - \\
\hline
\end{tabular}

*Dose do produto comercial utilizado por hectare em uma quantidade de $600 \mathrm{~L}$ de água 
TABELA 4. Eficiência relativa da mortalidade de lagartas $S$. frugiperda alimentadas com seções de folhas de soja imersas em inseticidas 24,48 , e 72 horas após implantação do experimento, calculada com base na mortalidade de lagartas Lagartas $1^{\circ}$ instar.

Inseticidas

Ingrediente ativo/grupo químico

$24 \mathrm{~h} 48 \mathrm{~h} 72 \mathrm{~h}$ Eficiência (\%)

Curyom 550 EC Lufenurom (500 g i.a L $\left.{ }^{-1}\right)$ / Benzoiluréia + Profenofós (50 g i.a L $\left.{ }^{-1}\right)$ / Organofosforado

$100-\quad-$

Endosulfan AG Endossulfan $\left(635 \mathrm{~g}^{\mathrm{i} . \mathrm{a} \mathrm{L}^{-1}}\right) /$ Ciclodienoclorado

Engeo Pleno Lambda-Cialotrina (106 g i.a L $\left.{ }^{-1}\right) /$ Piretróide + Tiametoxam (146 g i.a L L ${ }^{-1}$ / Neonicotinóide

Klorpan 480 EC Clorpirifós $\left(489,80 \mathrm{~g}\right.$ i.a $\left.\mathrm{L}^{-1}\right) /$ Organofosforado

$80100-$

'Dose do produto comercial utilizado por hectare em uma quantidade de $600 \mathrm{~L}$ de água

TABELA 5. Eficiência relativa da mortalidade de lagartas $S$. frugiperda alimentadas com seções de folhas de soja imersas em inseticidas 24, 48, e 72 horas após implantação do experimento, calculada com base na mortalidade de lagartas Lagartas $3^{\circ}$ instar.

\begin{tabular}{|c|c|c|c|c|}
\hline \multirow{2}{*}{ Inseticidas } & \multirow[t]{2}{*}{ Ingrediente ativo/grupo químico } & \multicolumn{3}{|c|}{$24 \mathrm{~h} 48 \mathrm{~h} 72 \mathrm{~h}$} \\
\hline & & Efic & ência & \\
\hline Curyom 550 EC & Lufenurom (500 g i.a L $\left.{ }^{-1}\right) /$ Benzoiluréia + Profenofós $\left(50 \mathrm{~g}\right.$ i.a L $\left.{ }^{-1}\right)$ / Organofosforado & 67 & 100 & - \\
\hline Endosulfan AG & Endossulfan $\left(635 \mathrm{~g}\right.$ i.a L $\left.{ }^{-1}\right) /$ Ciclodienoclorado & 100 & - & - \\
\hline Engeo Pleno & Lambda-Cialotrina (106 g i.a L L $)$ / Piretróide + Tiametoxam (146 g i.a L L ) / Neonicotinóide & 33 & 100 & - \\
\hline Klorpan 480 EC & Clorpirifós $\left(489,80 \mathrm{~g}\right.$ i.a $\left.\mathrm{L}^{-1}\right) /$ Organofosforado & 100 & - & - \\
\hline
\end{tabular}

*Dose do produto comercial utilizado por hectare em uma quantidade de $600 \mathrm{~L}$ de água. 
TABELA 6. Eficiência relativa da mortalidade de lagartas $S$. frugiperda alimentadas com seções de folhas de feijoeiro imersas em inseticidas 24, 48, e 72 horas após implantação do experimento, calculada com base na mortalidade de lagartas - Lagartas $1^{\circ}$ instar.

Inseticidas

Ingrediente ativo/grupo químico

$24 \mathrm{~h} 48 \mathrm{~h} 72 \mathrm{~h}$

Eficiência (\%)

Curyom 550 EC Lufenurom (500 g i.a L $\left.{ }^{-1}\right)$ / Benzoiluréia + Profenofós (50 g i.a L $\left.{ }^{-1}\right)$ / Organofosforado

100

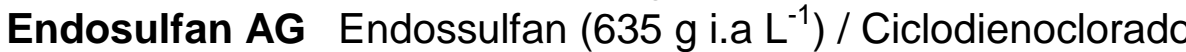

$-\quad-$

Engeo Pleno Lambda-Cialotrina (106 g i.a L $\left.{ }^{-1}\right) /$ Piretróide + Tiametoxam (146 g i.a L $\left.{ }^{-1}\right) /$ Neonicotinóide

$100-\quad-$

Klorpan 480 EC Clorpirifós $\left(489,80 \mathrm{~g}\right.$ i.a $\left.\mathrm{L}^{-1}\right) /$ Organofosforado

90100

${ }^{*}$ Dose do produto comercial utilizado por hectare em uma quantidade de 600 I de água

TABELA 7. Eficiência relativa da mortalidade de lagartas $S$. frugiperda alimentadas com seções de folhas de feijoeiro imersas em inseticidas 24, 48, e 72 horas após implantação do experimento, calculada com base na mortalidade de lagartas - Lagartas $3^{\circ}$ instar.

\begin{tabular}{|c|c|c|c|c|}
\hline \multirow[t]{2}{*}{ Inseticidas } & \multirow[t]{2}{*}{ Ingrediente ativo/grupo químico } & \multicolumn{3}{|c|}{$24 \mathrm{~h} 48 \mathrm{~h} 72 \mathrm{~h}$} \\
\hline & & Efic & êncic & \\
\hline Curyom 550 EC & Lufenurom (500 g i.a L $\left.{ }^{-1}\right) /$ Benzoiluréia + Profenofós $\left(50 \mathrm{~g}\right.$ i.a L $\left.{ }^{-1}\right)$ / Organofosforado & 100 & - & - \\
\hline Endosulfan AG & Endossulfan (635 g i.a L $\left.{ }^{-1}\right) /$ Ciclodienoclorado & 67 & 100 & - \\
\hline Engeo Pleno & Lambda-Cialotrina (106 g i.a L ${ }^{-1}$ ) / Piretróide + Tiametoxam (146 g i.a L ${ }^{-1}$ ) / Neonicotinóide & 67 & 100 & - \\
\hline Klorpan 480 EC & Clorpirifós (489,80 g i.a L $\left.\mathrm{L}^{-1}\right) /$ Organofosforado & 67 & 100 & - \\
\hline
\end{tabular}

${ }^{*}$ Dose do produto comercial utilizado por hectare em uma quantidade de 600 I de água. 
TABELA 8. Eficiência relativa da mortalidade de lagartas $S$. frugiperda alimentadas com seções de folhas de sorgo imersas em inseticidas 24, 48, e 72 horas após implantação do experimento, calculada com base na mortalidade de lagartas - Lagartas $1^{\circ}$ instar.

Inseticidas

Ingrediente ativo/grupo químico

$24 \mathrm{~h} 48 \mathrm{~h} 72 \mathrm{~h}$ Eficiência (\%)

Curyom 550 EC Lufenurom (500 g i.a L $\left.{ }^{-1}\right)$ / Benzoiluréia + Profenofós (50 g i.a L $\left.{ }^{-1}\right)$ / Organofosforado 100

Endosulfan AG Endossulfan $\left(635 \mathrm{~g}^{\mathrm{i} . \mathrm{a} \mathrm{L}^{-1}}\right) /$ Ciclodienoclorado

$90-100$

Engeo Pleno Lambda-Cialotrina (106 g i.a L $\left.{ }^{-1}\right) /$ Piretróide + Tiametoxam (146 g i.a L $\left.{ }^{-1}\right) /$ Neonicotinóide $80 \quad 90 \quad 100$

KIorpan 480 EC Clorpirifós $\left(489,80 \mathrm{~g}^{\left.\mathrm{i} . \mathrm{a} \mathrm{L}^{-1}\right)} /\right.$ Organofosforado

100

${ }^{\star}$ Dose do produto comercial utilizado por hectare em uma quantidade de 600 I de água

Fonte: Elaboração própria

TABELA 9. Eficiência relativa da mortalidade de lagartas $S$. frugiperda alimentadas com seções de folhas de sorgo imersas em inseticidas 24, 48, e 72 horas após implantação do experimento, calculada com base na mortalidade de lagartas - Lagartas $3^{\circ}$ instar.

Inseticidas

Ingrediente ativo/grupo químico

$24 \mathrm{~h} 48 \mathrm{~h} 72 \mathrm{~h}$

Eficiência (\%)

Curyom 550 EC Lufenurom (500 g i.a L $\left.{ }^{-1}\right)$ / Benzoiluréia + Profenofós (50 g i.a L $\left.{ }^{-1}\right) /$ Organofosforado

$67100 \quad-$

Endosulfan AG Endossulfan (635 g i.a L ${ }^{-1}$ ) / Ciclodienoclorado

Engeo Pleno Lambda-Cialotrina (106 g i.a L $\left.{ }^{-1}\right) /$ Piretróide + Tiametoxam (146 g i.a L $\left.{ }^{-1}\right) /$ Neonicotinóide 100

Klorpan 480 EC Clorpirifós $\left(489,80 \mathrm{~g}^{\text {i.a L L }}{ }^{-1}\right) /$ Organofosforado

$33100-$

${ }^{*}$ Dose do produto comercial utilizado por hectare em uma quantidade de 600 I de água

Fonte: Elaboração própria 
Todos os inseticidas testados têm mecanismo de ação neurotóxica que, segundo BUSATO et al. (2006) atuam mais rapidamente sobre a morte dos insetos, enquanto que os inibidores da síntese da quitina agem mais lentamente quanto aos distúrbios ocasionados sobre a fisiologia do mesmo. Possivelmente esse fato contribuiu para relativa rapidez em promover a mortalidade de $100 \%$ das lagartas de $S$. frugiperda de $1^{\circ}$ e $3^{\circ}$.

A velocidade de atuação mais ou menos lenta sobre a mortalidade das populações de insetos-praga dos inseticidas foi constatada em diversos trabalhos. CESSA et al. (2013) constataram que inseticidas neurotóxicos com ação de "choque", quando utilizados isoladamente ou em mistura com outros inseticidas tiveram, em geral, eficiência relativa sobre a mortalidade de $S$. frugiperda em até 48 horas, e que aqueles reguladores do crescimento dos insetos utilizados isoladamente tiveram eficiência relativa superior a $80 \%$ sobre a mortalidade de lagartas $S$. frugiperda a partir do terceiro dia.

WANGEN e colaboradores (2015) estudando os inseticidas Lambdacialotrina+Chlorantraniliprole, Metoxifenozida, Cipermetrina, Clorpirifós no controle de $S$. frugiperda, não constataram eficiência significativa, os resultados foram abaixo do mínimo recomendado pelo Ministério da Agricultura, Pecuária e Abastecimento.

RODRIGUES e colaboradores (2009) observou a eficiência relativa superior a $80 \%$ no controle da população de Alabama argillacea com uso de metomil (172 g de i.a ha ${ }^{-1}$ ) e Bacillus thuringiensis + metomil (172 $\left.\mathrm{g}^{\text {de i.a ha }}{ }^{-1}\right)$ dois dias após pulverização, exaltando o efeito de "choque" proporcionado pelo metomil sobre a praga. Para esse período de avaliação os autores não observaram eficiência relativa com uso do inseticida diflubenzurom.

\section{CONCLUSÕES}

Nos períodos de 48 e 72 horas após implantação do ensaio observou-se eficiência relativa de $100 \%$ sobre a mortalidade das lagartas $S$. frugiperda de $1^{\circ}$ e e $3^{\circ}$ instar respectivamente quando alimentada com folhas de milho, soja e feijoeiro.

O maior período (72 horas após implantação do ensaio) observado para obtenção da eficiência relativa de $100 \%$ sobre a mortalidade de lagartas de $S$. frugiperda de $1 \stackrel{0}{\circ}$ instar foi constatado com uso de Engeo Pleno e Endosulfan AG em feijoeiro e sorgo.

Dentre os fatores pertinentes à velocidade na obtenção de $100 \%$ de eficiência relativa sobre a mortalidade das lagartas de $S$. frugiperda de $1^{\circ}$ e $3^{\circ}$ pode-se citar 0 mecanismo de ação como um dos mais importantes.

\section{REFERÊNCIAS}

ABBOTT, W. S. A method of computing the effectiveness of on insecticide. Journal of Economic Entomology, Lanham, v. 18, n. 1, p. 265-267. 1925.

ARAÚJO, L. F. de; SILVA, A. G. da; CRUZ, I.; CARMO, E. L. do; HORVATH NETO, A.; GOULART, M. M. P.; RATTES, J. F. Flutuação populacional de Spodoptera frugiperda (J. E. Smith), Diatraea saccharalis (Fabricius) e Doru luteipes (Scudder) em milho convencional e transgênico Bt. Revista Brasileira de Milho e Sorgo, Sete Lagoas, v. 10, n. 3, p. 205-214, 2011.

BELLETTINI, S.; BELLETTINI, N. M. T.; NISHIMURA, M.; BELLETTINI, R.; FONTES, T. B.; FONTES NETO, D. T.; CARVALHO, F. K. Controle da Spodoptera 
frugiperda (J. E. Smith, 1797) com inseticidas no algodoeiro. In: CONGRESSO BRASILEIRO DE ALGODÃO, 8; COTTON EXPO, 1.; São Paulo. Evolução da cadeia para construção de um setor forte: Anais... Campina Grande, PB: Embrapa Algodão, 2011. p. 123-127 (CD-ROM).

BUSATO, G. R.; GRÜTZMACHER, A. D.; GARCIA, M. S.; ZOTTI, M. J.; NÖRNBERG, S. D.; MAGALHÃES, T. R.; MAGALHÃES, J. De BANDEIRAS. Susceptibilidade de lagartas dos biótipos milho e arroz de Spodoptera frugiperda (J.E. Smith, 1797) (Lepidoptera: Noctuidae) a inseticidas com diferentes modos de ação. Ciência Rural, Santa Maria, v. 36, n. 1 p. 15-20, 2006.

CAMPANHA, M. M.; CRUZ, J. C.; RESENDE, A. V.; COELHO, A. M.; KARAM, D.; SILVA, G. H. da; PEREIRA FILHO, I. A.; CRUZ, I.; MARRIEL, I. E.; GARCIA, J. C.; QUEIROZ, L. R.; PIMENTEL, M. A. G.; GONTIJO NETO, M. M.; VIANA, P. A.; ALBUQUERQUE, P. E. P de; COSTA, R. V. da; MENDES, S. M.; QUEIROZ, V. A. Sistema de produção integrada de milho para Região Central de Minas Gerais. Sete Lagoas: Embrapa Milho e Sorgo, 2012. 74 p. (Documentos: Embrapa Milho e Sorgo).

CESSA, R. M. A.; MELO, E. P. D.; LIMA JUNIOR, I. Dos S. De. Mortalidade de Spodoptera frugiperda (J. E. Smith) (Lepdoptera: noctuidae) alimentadas com folhas de milho e feijoeiro imersas em soluções contendo inseticidas. Revista Agrogeoambiental, Pousada Alegre, v. 5, n. 1, p. 1-7, 2013.

DIEZ-RODRIGUEZ, G. I.; OMOTO, C. Herança da resistência de Spodoptera frugiperda (J.E. Smith) (Lepidoptera: Noctuidae) a lambda-cialotrina. Neotropical Entomology, Londrina, v. 30, p. 311-316, 2001.

GALLO, D.; NAKANO, O.; SILVEIRA NETO, S.; CARVALHO, R. P. L.; BAPTISTA, G. C. de; BERTI FILHO, E.; PARRA, J. R. P.; ZUCCHI, R. A.; ALVES, S. B.; VENDRAMIM, J. D.; MARCHINI, L. C.; LOPES, J. R. S.; OMOTO, C. Entomologia agrícola. Piracicaba: Fealq, 2002. 920 p.

MICHELOTTO, M. D.; FINOTO, E. L.; MARTINS, A. L. M.; DUARTE A. P. Interação entre transgênicos (Bt) e inseticidas no controle de pragas-chave em híbridos de milho-safrinha. Arquivos do Instituto Biológico, São Paulo, v.78, n.1, p.71-79, 2011.

OTA, É. C.; LOURENÇÃO, A. L.; DUARTE, A. P.; RAMOS JUNIOR, E. U.; ITO, M. A. Desempenho de cultivares de milho em relação à lagarta-do-cartucho. Bragantia, Campinas, v. 70, n. 4, p. 850-859, 2011.

RODRIGUES, R. B.; ARNEMANN, J. A.; FERREIRA, P.; GUEDES, J. V. C.; DALAZEN, G. Eficiência de inseticidas no controle de curuquerê do algodão Alabama argillacea HUEB., 1818 (LEPIDOPTERA: NOCTUIDAE). In: CONGRESSO BRASILEIRO DO ALGODÃO, 7. 2009, Foz do Iguaçu. Anais... Campina grande: Embrapa Algodão, 2009. p. 633-638. 
SILVA, D. M.; BUENO, A. F.; MANTOVANI, M. A. M.; STECCA, S. C.; LEITE, N.; OLIVEIRA, M. C. N.; MOSCARDI, F. Biologia e preferência alimentar de Spodoptera frugiperda (Lepidoptera: Noctuidae) em diferentes fontes hospedeiras. In: VI CONGRESSO BRASILEIRO DE SOJA, 6., 2012, Cuiabá. Anais... Cuiabá: Embrapa Algodão, p. 1-5.2012.

TOSCANO, L. C.; CALADO FILHO, G. C.; CARDOSO A. M.; MARUYAMA, W. I.; TOMQUELSKI, G. V. Impacto de inseticidas sobre Spodoptera frugiperda (Lepidoptera, Noctuidae) e seus inimigos naturais em milho safrinha cultivado em Cassilândia e Chapadão do sul, MS. Arquivo Instituto Biológico, São Paulo, v.79, n.2, p.223-231, 2012.

WANGEN, D. R. B.; PEREIRA JÚNIOR, P. H. S.; SANTANA, W. S. Controle de Spodoptera frugiperda (J. E. Smith, 1797) na cultura do milho com inseticidas de diferentes grupos químicos. Enciclopédia Biosfera, Goiânia, v. 11, n. 22, p. 801 $808,2015$. 